\title{
Interference control, working memory, concept shifting, and verbal fluency in adults with attention- deficit/hyperactivity disorder (ADHD)
}

Citation for published version (APA):

Marchetta, N. D. J. M., Hurks, P. P. M., Krabbendam, L., \& Jolles, J. (2008). Interference control, working memory, concept shifting, and verbal fluency in adults with attention-deficit/hyperactivity disorder (ADHD). Neuropsychology, 22(1), 74-84. https://doi.org/10.1037/0894-4105.22.1.74

Document status and date:

Published: 01/01/2008

DOI:

10.1037/0894-4105.22.1.74

Document Version:

Publisher's PDF, also known as Version of record

Please check the document version of this publication:

- A submitted manuscript is the version of the article upon submission and before peer-review. There can be important differences between the submitted version and the official published version of record.

People interested in the research are advised to contact the author for the final version of the publication, or visit the DOI to the publisher's website.

- The final author version and the galley proof are versions of the publication after peer review.

- The final published version features the final layout of the paper including the volume, issue and page numbers.

Link to publication

\footnotetext{
General rights rights.

- You may freely distribute the URL identifying the publication in the public portal. please follow below link for the End User Agreement:

www.umlib.nl/taverne-license

Take down policy

If you believe that this document breaches copyright please contact us at:

repository@maastrichtuniversity.nl

providing details and we will investigate your claim.
}

Copyright and moral rights for the publications made accessible in the public portal are retained by the authors and/or other copyright owners and it is a condition of accessing publications that users recognise and abide by the legal requirements associated with these

- Users may download and print one copy of any publication from the public portal for the purpose of private study or research.

- You may not further distribute the material or use it for any profit-making activity or commercial gain

If the publication is distributed under the terms of Article $25 \mathrm{fa}$ of the Dutch Copyright Act, indicated by the "Taverne" license above, 


\title{
Interference Control, Working Memory, Concept Shifting, and Verbal Fluency in Adults With Attention-Deficit/Hyperactivity Disorder (ADHD)
}

\author{
Natalie D. J. Marchetta, Petra P. M. Hurks, and \\ Lydia Krabbendam \\ Maastricht University
}

\author{
Jelle Jolles \\ Maastricht University and Vijverdal Psychiatric Hospital \\ Maastricht
}

\begin{abstract}
In this study, the authors aimed to examine 4 domains of executive functioning in adults with attention-deficit/hyperactivity disorder (ADHD)—namely interference control, concept shifting, verbal fluency, and verbal working memory. Four groups of participants were included: (a) adults diagnosed with ADHD (ADHD $; n=20$ ), (b) adults diagnosed with both ADHD and 1 or more comorbid disorder(s) $\left(\mathrm{ADHD}^{+} ; n=22\right)$, (c) adults referred for ADHD because of ADHD symptomatology but not diagnosed as such (non-ADHD; $n=34$ ), and (d) healthy controls $(n=136)$. ADHD-related deficits (independent of comorbidity) were revealed for concept shifting and verbal working memory. In addition, the $\mathrm{ADHD}^{+}$and non-ADHD groups displayed deficits in terms of general processing speed. Given that these deficits were not found in the $\mathrm{ADHD}^{-}$group, the authors contend that these deficits are likely attributable to comorbidity rather than ADHD itself. Contrary to the authors' expectations, these findings do not correspond with the cognitive subtype hypothesis.
\end{abstract}

Keywords: ADHD, adults, executive functioning, comorbidity

Attention-deficit/hyperactivity disorder (ADHD) is marked by a triad of core symptoms, namely inattention, hyperactivity, and impulsivity (American Psychiatric Association [APA], 1994). Although ADHD has historically been regarded as a childhood disorder, evidence indicates that ADHD persists into adulthood for $50 \%-80 \%$ of all individuals ever diagnosed with ADHD (Biederman et al., 1995, 1998; Manuzza \& Klein, 2000; Weiss \& Trokenberg-Hechtman, 1993). Clearly, ADHD can and does have a significant impact on many individuals in adulthood. These individuals often experience problems with organization, discipline, and setting priorities. Additionally, they are often accident prone and have difficulty maintaining a stable job or marriage (Barkley, Murphy, \& Kwasnik, 1996; Faraone et al., 2000).

An involvement of prefrontal regions and other interconnected subcortical structures (e.g., the cerebellum and caudate nucleus), underlying an executive dysfunction, has been found in both children and adults with ADHD (Biederman \& Faraone, 2002; Bush et al., 1999; Durston, 2003; Rubia et al., 1999; Seidman,

Natalie D. J. Marchetta and Lydia Krabbendam, Department of Psychiatry and Neuropsychology, Maastricht University, Maastricht, the Netherlands; Petra P. M. Hurks, Department of Psychiatry and Neuropsychology, and Department of Psychology, Maastricht University; Jelle Jolles, Department of Psychiatry and Neuropsychology, and Department of Psychology, Maastricht University, and Vijverdal Psychiatric Hospital Maastricht, Maastricht, the Netherlands.

We wish to thank Jurgen Cornelis and Ben Hirsch, members of the attention-deficit/hyperactivity disorder (ADHD) multidisciplinary team, for their clinical expertise and cooperation.

Correspondence concerning this article should be addressed to Natalie D. J. Marchetta or Petra P. M. Hurks, Department of Psychiatry and Neuropsychology, Maastricht University, 6200 MD Maastricht, P.O. Box 616, the Netherlands. E-mail: nathalie.marchetta@np.unimaas.nl or p.hurks@np.unimaas.nl
Valera, \& Makris, 2005; Vaidya et al., 1998). Researchers are taking an increasingly greater interest in the measurement of inputand output-related information processes to evaluate the hypothesis of an underlying brain dysfunction in ADHD. The primary focus is on tests measuring deficits in executive functioning (EF; Barkley, 1998). The term EF is a multidimensional construct that refers to a set of higher order cognitive functions necessary for goal-directed and contextually appropriate behavior (Lezak, 1995; Spreen \& Strauss, 1998). Cognitive operations related to EF include the following: initiation, planning, hypothesis generation, cognitive flexibility, decision making, regulation, judgment, feedback utilization, self-perception, response inhibition, interference control, working memory, planning, cognitive flexibility, and fluency (Denckla, 1996; Pennington \& Ozonoff, 1996). Although the hypothesized EF deficits have been explored extensively in children, to date, little research has been conducted on EF deficits in adults with ADHD, and the studies that have been conducted have generated inconsistent results (Dinn, Robbins, \& Harris, 2001; Gansler et al., 1998; Hervey, Epstein, \& Curry, 2004; Holdnack et al., 1995; Johnson et al., 2001; Lovejoy et al., 1999; K. R. Murphy, Barkley, \& Bush, 2001; P. Murphy, 2002; Rapport, Van Voorhis, Tzelepis, \& Friedman, 2001; Seidman, Biederman, Weber, Hatch, \& Faraone, 1998; Seidman et al., 2004; Sergeant, Geurts, \& Oosterlaan, 2002; Walker, Shores, Trollor, Lee, \& Sachdev, 2000; Woods, Lovejoy, \& Ball, 2002). Some researchers have found that adults with ADHD, when compared with healthy control participants, perform poorer on (a) interference control-for example, using the Stroop Color-Word Test (SCWT; Stroop, 1935)—(Dinn et al., 2001; K. R. Murphy et al., 2001; Rapport et al., 2001); (b) mental flexibility - for example, the Trail Making Test (which is a subtest of the Halstead-Reitan Battery (Reitan, 1958)—(Gansler et al., 1998; Holdnack et al., 1995; Lovejoy et al., 1999); and (c) semantic verbal fluency (Lovejoy et al., 1999; Walker et al., 2000). At the same time, other studies have demonstrated no differences 
between adults with ADHD and healthy control participants for the Trail Making Test (Walker et al., 2000) and verbal fluency (Barkley et al., 1996; Johnson et al., 2001). Because of this lack of clarity, we endeavored, in our study, to evaluate differences in a subset of executive functions in four groups of adults, namely adults with $\mathrm{ADHD}\left(\mathrm{ADHD}^{-}\right)$, adults with comorbid $\mathrm{ADHD}$ $\left(\mathrm{ADHD}^{+}\right)$, adults with nondiagnosed ADHD (non-ADHD), and healthy control participants.

When examining EF in individuals with ADHD, and when considering the inconsistent results of previous studies, a number of issues should be considered. First, we should be aware that the EF domain is nonunitary and that performance measures are only modestly correlated (Nigg, Blaskey, Huang-Pollock, \& Rappley, 2002). EF is a broad domain, and the specification of the components in this domain should be carefully considered (Barkley, 1997; Pennington \& Ozonoff, 1996). Unfortunately, the precise specification of subdomains is still being debated. Therefore, for the purposes of the current study, we included a limited number of EF domain components. These were chosen in accordance with Pennington and Ozonoff's (1996) classification system and included the following: (a) interference control, which is defined as protection from self-directed responses that result from disruption by competing events and responses; (b) concept shifting, which is the ability to regulate one's own behavior or to shift a course of thought or action according to the demands of the situation; (c) verbal fluency, which is the ability to generate spontaneous verbal production and organization while relying on rule-governed strategies for retrieval of verbal information under time constraints; and (d) verbal working memory, which is a buffer in which a limited amount of information can be actively retained over a relatively short period of time.

The second issue that should be considered when examining EF and ADHD is that earlier studies have suggested that EF tasks may also tap into non-EF tasks-such as attention capacity and information processing speed (Nigg et al., 2002; Pennington \& Ozonoff, 1996; Sergeant et al., 2002). To determine whether poor performance on an EF task is due to either working memory, verbal fluency, concept shifting, or interference control, researchers need to include control tasks that measure non-EF functions (Sergeant et al., 2002). Consequently, the study presented here included assessments that would control for non-EF functions. More specifically, we used an assessment of output response speed - a factor found to be impaired in individuals with ADHD (Nigg et al., 2002) — as a control for non-EF demands and for its relevance to associated functions, such as effort.

A third issue that needs to be considered is that ADHD in adults often co-occurs with other psychiatric conditions, including antisocial and other personality disorders, substance abuse, anxiety, mood disorders, and learning disabilities. The prevalence of comorbid disorders is not incidental. Comorbidity occurs in 30\%$60 \%$ of all adults with ADHD (Milberger, Biederman, Faraone, Murphy, \& Tsuang, 1995; Millstein, Wilens, Biederman, \& Spencer, 1997; K. R. Murphy, Barkley, \& Bush, 2002). Many of the comorbid disorders associated with ADHD are known to directly affect the cognitive abilities of the individual (Pennington \& Ozonoff, 1996; Seidman, Biederman, Faraone, Weber, \& Ouellette, 1997). Therefore, it is difficult to determine whether cognitive deficits are attributable to ADHD or to the presence of the comorbid disorder or to both. Only a few studies have examined the extent to which EF deficits are actually a function of ADHD by controlling for comorbidity (i.e., K. R. Murphy et al., 2001; Seidman et al., 1998; Walker et al., 2000). This is unfortunate, as failing to control for the impact of comorbid symptoms weakens the validity of neuropsychological investigations in clinical settings (Walker et al., 2000). Therefore, in the present study, we controlled comorbidity in two ways. First, we employed a subgroup comparison in which a group of adults with comorbidity $\left(\mathrm{ADHD}^{+}\right)$were compared with a group of adults without comorbidity $\left(\mathrm{ADHD}^{-}\right)$. According to the cognitive subtype hypothesis (Rucklidge \& Tannock, 2002), the co-occurrence of ADHD together with another syndrome generates a third disorder that is due, at least in part, to etiological factors that are distinct from those that increase susceptibility to both disorders alone. This hypothesis thus predicts that the comorbid group would exhibit a different pattern of external correlates than would be expected on the basis of the additive combination of the correlates of each disorder when they occur separately. This hypothesis corresponds with the findings reported by Oosterlaan, Logan, and Sergeant (1998). These authors demonstrated that children with ADHD and comorbid oppositional defiant disorder/obsessive-compulsive disorder had enhanced EF deficits when compared with children with only ADHD or only oppositional defiant disorder/obsessive-compulsive disorder. Unfortunately, researchers who have investigated this hypothesis in studies focusing on adults have obtained inconclusive results. In the present study, we investigate this hypothesis in relation to adults in detail. The second means by which we controlled for comorbidity was done by including a clinically referred control group (non-ADHD). This group was comprised of individuals who had been referred for potential diagnosis because they exhibited ADHD symptoms but, upon assessment, did not meet the diagnostic criteria for ADHD. Members of this group may display psychopathology other than ADHD or no psychopathology at all. Nonetheless, the inclusion of this group as a control group was considered interesting for the determination of differences in neurocognitive dysfunction, given the fact that this group had previously been referred for the clinical assessment of ADHD symptomatology.

In summary, our primary goal in the present study was to investigate the performance of adults with and without ADHD on four executive domains-namely interference control, concept shifting, working memory, and verbal fluency-and on one non-EF domain, namely processing speed. Our second goal was to determine the impact of comorbidity and the specificity of EF deficits in adults with ADHD. This was done by comparing adults with relatively pure $\mathrm{ADHD}\left(\mathrm{ADHD}^{-}\right)$to adults with both $\mathrm{ADHD}$ and at least one comorbid disorder $\left(\mathrm{ADHD}^{+}\right)$and also to clinically referred non-ADHD adults. On the basis of previous studies, we first hypothesized that participants with ADHD would show impairments on all four EF domains. We also hypothesized that, if the ADHD groups with and without comorbidity performed differently than the healthy control group, this difference would be attributable to the presence of ADHD. Further, we hypothesized that if the $\mathrm{ADHD}^{+}$group and non-ADHD group performed differently than the $\mathrm{ADHD}^{-}$group and/or healthy controls, this difference would be attributable to the presence of comorbidity in both groups. If only the $\mathrm{ADHD}^{+}$group would perform differently than the healthy control or non-ADHD groups, this would be attributable to ADHD and/or comorbidity differences in the 
groups. We also expected that the $\mathrm{ADHD}^{+}$group would show more pronounced and more specific deficits when compared with the $\mathrm{ADHD}^{-}$group and the non-ADHD group. This expectation was based on the cognitive subtype hypothesis, which posits that the impact of comorbid disorders is more than the sum of each separate disorder (Rucklidge \& Tannock, 2002). In selecting our sample, we only included young adults $20-41$ years of age given the existence of age-related changes in neurocognitive function for middle-age participants (Houx, Jolles, \& Vreeling, 1993; Houx, Vreeling, \& Jolles, 1991; Salthouse, 1996).

\section{Method}

\section{Participants}

Participants in the $\mathrm{ADHD}^{-}, \mathrm{ADHD}^{+}$, and non-ADHD groups were clinically referred by a medical specialist to the outpatient facility for adults with ADHD at Vijverdal Psychiatric Hospital Maastricht (the Netherlands). The participants were consecutive referrals recruited over a period of 5 years from 1998 to 2003. At the time of referral, all individuals exhibited one or more ADHD symptoms and sought the help of a medical specialist who then referred them to this specialized outpatient clinic. Participant characteristics of all groups are presented in Table 1. A multidisciplinary diagnostic assessment, which corresponds with procedures used in other studies (i.e., Barkley, Murphy, \& Bush, 2001; Barkley, Murphy, DuPaul, \& Bush, 2002; Walker et al., 2000), was applied at Vijverdal Psychiatric Hospital Maastricht. The diagnostic assessment consisted of standardized psychiatric and (neuro) psychological diagnostic and research protocols. This included a semistructured diagnostic interview and a clinical interview with both the patient and a cross-informant (usually a parent or a spouse), both of which were conducted by experienced psychiatrists or health care psychologists. In addition, self-reported rating scales were completed by the patient, both at home and at the diagnostic center. Furthermore, a neuropsychological examination-including well-established tests measuring intelligence and attention and the experimental tasks described in this article-was conducted. Lastly, a review of school reports (if available) was done. The diagnosis was reached by a multidisciplinary ADHD team of board certificated psychiatrists and licensed health care psychologists/clinical neuropsychologists. The diagnosis was determined by clinical consensus ratings of all the available data from the interviews (including medical and psychosocial history taking) and the neuropsychological assessment. All individuals in the $\mathrm{ADHD}^{-}$group received a diagnosis based on Diagnostic and
Statistical Manual of Mental Disorders (4th ed.; DSM-IV; APA, 1994) diagnostic criteria of ADHD by referring to both current symptoms and retrospective symptoms of childhood ADHD (ADHD combined type: $n=15$; ADHD predominantly inattentive type: $n=5$ ). Individuals included in the $\mathrm{ADHD}^{-}$group displayed no comorbidity. All participants included in the $\mathrm{ADHD}^{+}$group (ADHD combined type: $n=17$; ADHD predominantly inattentive type: $n=5$ ) met the criteria for both ADHD and at least one other $D S M-I V$ classification (see Table 2 for an overview of comorbid disorders). The non-ADHD group was composed of individuals who, although having been referred for assessment because they displayed ADHD symptoms, did not meet the diagnostic criteria for the disorder $(n=34)$. A high percentage of the adults in this group had at least one DSM-IV classification other than ADHD (see Table 2 for group characteristics regarding DSM-IV diagnoses).

The healthy control group (matched with ADHD and non-ADHD participants for gender, age, and IQ; $n=136$ ) was derived from a large $(N=1,823)$ cross-sectional and longitudinal study, called the Maastricht Aging Study (MAAS; Jolles, Houx, Van Boxtel, \& Ponds, 1995; Van Boxtel et al., 1998). These MAAS participants can be regarded as historical controls (Campbell \& Stanley, 1963). The procedure for recruitment of the healthy control participants in the MAAS study has been described in detail elsewhere (Jolles et al., 1995; Van Boxtel et al., 1998). In short, participants in the MAAS study were randomly drawn from the Registration Network of Family Practices, which is a sample frame for research in health care practice (Metsemakers, Höppener, Knottnerus, Kocken, \& Limonard, 1992). Individuals were invited to participate in the study by their general practitioners, rather than by the project staff, because this was expected to generate greater participation and study compliance. They were also screened by this practitioner for psycho-social contraindications to participation, such as actual major life events. After agreeing to participate, a postal survey questionnaire was sent to the participants. At the same time, the participants were asked whether they were also willing to participate in the additional test program. Healthy participants were selected from the same region, namely the southern region of the Netherlands, as the clinical participants. Additionally, the health control participants in the MAAS study were between 24 and 81 years of age at the time of the study. For the purpose of this study, only healthy control participants in the same age range as the adults with ADHD were included.

Exclusion criteria for all four groups included the following: (a) serious head trauma, including organic syndromes, such as meningitis; (b) the presence of neurological pathology or medical

Table 1

Participant Characteristics

\begin{tabular}{|c|c|c|c|c|c|c|}
\hline Variable & $\begin{array}{l}\mathrm{ADHD}^{-} \\
(n=20)\end{array}$ & $\begin{array}{l}\mathrm{ADHD}^{+} \\
(n=22)\end{array}$ & $\begin{array}{l}\text { Non-ADHD } \\
(n=34)\end{array}$ & $\begin{array}{c}\text { Controls } \\
(n=136)\end{array}$ & $F$ & $x^{2}$ \\
\hline Gender (\% women $)^{\mathrm{a}}$ & 25.0 & 27.3 & 47.1 & 38.2 & & 3.676 \\
\hline Medication $(\% \text { yes })^{\mathrm{a}}$ & 15.0 & 40.9 & 38.2 & 0.0 & & $59.165^{* * *}$ \\
\hline Age $(M, S D)^{\mathrm{b}}$ & $29.95(5.22)$ & $31.34(5.32)$ & $28.81(5.92)$ & $30.13(4.79)$ & 1.162 & \\
\hline $\mathrm{IQ}(M, S D)$ & $103.55(8.55)$ & $108.36(12.86)$ & $102.59(11.27)$ & $105.22(11.29)$ & 1.306 & \\
\hline
\end{tabular}

Note. $\mathrm{ADHD}=$ attention-deficit/hyperactivity disorder; $\mathrm{ADHD}^{-}=\mathrm{ADHD}$ without comorbidity; $\mathrm{ADHD}^{+}=\mathrm{ADHD}$ with comorbidity.

${ }^{a}$ Pearson chi-square test. ${ }^{\mathrm{b}}$ The age range was $20-41$ years at the time of the neuropsychological investigation.

***** $p<.001$. 
Table 2

Distribution of Psychopathology Other Than ADHD in the Clinically Referred Groups

\begin{tabular}{|c|c|c|}
\hline$D S M-I V$ disorder & $\mathrm{ADHD}^{+}$ & non-ADHD \\
\hline No $D S M$ disorder & & 7 \\
\hline Mood disorder & 4 & 4 \\
\hline Anxiety disorder & 3 & 1 \\
\hline PD & 8 & 8 \\
\hline Substance-related disorders & 3 & \\
\hline Communication disorder & & 1 \\
\hline Adaptation disorder & & 1 \\
\hline Mood disorder and anxiety disorder & 1 & \\
\hline Mood disorder and PD & & 1 \\
\hline PD and substance-related disorder & & 5 \\
\hline PD and PTSD & & 2 \\
\hline PD and eating disorder & & 1 \\
\hline Substance-related disorders and PTSD & & 1 \\
\hline Mood disorder and PD and substance-related disorders & 1 & \\
\hline PD and substance-related disorder and eating disorder & & 1 \\
\hline $\begin{array}{l}\text { Mood disorder and PD and substance-related disorders } \\
\text { and panic disorder with agoraphobia in remission }\end{array}$ & 1 & \\
\hline Mood disorder and PD and PTSD and psychosis NOS & 1 & \\
\hline $\begin{array}{l}\text { Mood disorder and PD and anxiety disorder and PTSD } \\
\text { and bulimia nervosa }\end{array}$ & & 1 \\
\hline
\end{tabular}

Note. $\mathrm{ADHD}=$ attention-deficit/hyperactivity disorder; $\mathrm{ADHD}^{+}=\mathrm{ADHD}$ with comorbidity; $\mathrm{PD}=$ personality disorder, PTSD = posttraumatic stress disorder; NOS $=$ not otherwise specified.

disease(s), such as epilepsy, dementia, cerebrovascular disease, parkinsonism, malignancies related to the nervous system, and diabetes mellitus; and (c) an IQ score less than 85. ADHD and non-ADHD participants taking medication other than stimulants (i.e., antidepressants) were not excluded. All clinical participants were asked to discontinue their stimulant medication treatment 24 $\mathrm{hr}$ prior to the testing if this was the case, as this could have influenced their task performance (Hervey et al., 2004). Additional exclusion criteria for the healthy control sample were as follows: (a) psychopathology, including $\mathrm{ADHD}$, learning disabilities, and other psychiatric disorders; and (b) current chronic psychotropic drug use, such as medication, alcohol, and drugs-as these also co-occur in adults with ADHD, and these substances can influence task performance. None of the healthy control participants were taking medication at the time of the study. In total, 212 adults were included in the study $\left(\mathrm{ADHD}^{+}, n=22 ; \mathrm{ADHD}^{-}, n=20\right.$; non-ADHD, $n=34$; healthy control participants, $n=136$ ).

\section{Procedures}

All $\mathrm{ADHD}^{-}, \mathrm{ADHD}^{+}$, and non-ADHD participants were individually tested. Each completed a comprehensive clinical neuropsychological evaluation at Vijverdal Psychiatric Hospital Maastricht sometime between 1998 and 2003. The cognitive tests selected for the present study were part of an extensive neuropsychological test battery that included attention, planning, other memory tests, as well as psychological questionnaires. This battery of tests was administered to all participants in the same sequence. The neuropsychological investigation and collection of data were conducted under the supervision of several experienced and licensed health care psychologists/neuropsychologists. The procedure for all healthy participants in the MAAS study, including the subgroup selected for this study, consisted of a baseline test program (from 1993 to 1995) that used the neuropsychological tests described in this article and an additional questionnaire. The data for the healthy control participants were collected by test assistants who had been extensively trained in test administration by neuropsychologists and a physician who was also part of the project staff. All participants provided informed consent for participation in the study in written form.

\section{Measures of EF and Non-EF}

We selected the following cognitive tests to represent a subset of four major EF domains, namely interference control, mental flexibility, verbal fluency, and verbal working memory (Pennington \& Ozonoff, 1996). To measure non-EF demands reflected by information processing speed and attention, we utilized the first components of the SCWT and the Concept Shifting Test (CST; Reitan, 1958). These components of the EF battery and tests are not exhaustive but were chosen because they are sensitive to prefrontal lobe damage (Lezak, 1995), and given that prefrontal dysfunctions are also associated with ADHD (Durston, 2003), we considered these tests most appropriate for our study.

\section{Interference Control}

SCWT. The SCWT involves three subtests that include 100 stimuli each in a $10 \times 10$ matrix (Hammes, 1973; Stroop, 1935). Participants were asked to read words (Card I) or call out names of the colors represented by colored patches (Card II) as fast as possible. Subsequently, during Card III, participants were asked to name the color of the ink in which a color name was printed. Performance on Card III is largely determined by the time taken to discard irrelevant but very salient information (i.e., verbal reading) in favor of a less obvious aspect (i.e., color naming). The SCWT is a measure of general information processing speed (reading), (selective) attention, inhibition, and interference susceptibility 
(Houx et al., 1993; Lezak, 1995; Stroop, 1935). The dependent variable was the averaged total time to complete Card I and Card II (SCWT_12 = [Card I + Card II $] / 2$ ) as a non-EF control measure of information processing speed. The total time required to complete Card III (SCWT_3) and the interference score (SCWT interference $=$ SCWT_3 - SCWT_12) were used as measures of interference control that proved to be valid in previous studies (Valentijn et al., 2005; Van der Elst, Van Boxtel, Van Breukelen, \& Jolles, 2006b).

\section{Mental Flexibility}

CST. The CST is a modified version of the Trail Making Test, which is a subtest of the Halstead-Reitan Battery (Reitan, 1958) and is often used to measure information processing speed, (divided) attention, simple motor speed, visual conceptual and visuomotor tracking, and mental flexibility (Houx \& Jolles, 1993; Houx et al., 1991; Jolles et al., 1995; Vink \& Jolles, 1985). During the administration of Cards $\mathrm{A}$ and $\mathrm{B}$, the participant was asked to cancel out consecutively numbered circles on a worksheet (Card A) and then the same number of consecutively lettered circles (Card B). In Card C, the participant was asked to cancel out the same number of consecutively numbered and lettered circles on another worksheet by alternating between the two sequences (i.e., $1-\mathrm{A}, 2-\mathrm{B})$. The dependent measure was the averaged total time to complete Card A and B (CST_AB $=[$ Card A + Card B]/2) as a non-EF control measure of information processing speed. Total time to complete Card C (CST_C) and the CST shifting score $\left(\mathrm{CST}\right.$ shifting $=\mathrm{CST}$ C $\left.-\mathrm{CST} \_\mathrm{AB}\right)$ were used as a measure of mental flexibility (Valentijn et al., 2005; Van der Elst, Van Boxtel, Van Breukelen, \& Jolles, in press).

\section{Verbal Fluency}

Verbal Fluency Test (VFT). The VFT is a subtask of the Groningen Intelligence Test (GIT; Luteijn \& van der Ploeg, 1983). In the VFT, participants were asked to name as many words as they could that related to a predefined semantic category (i.e., animals, professions) for $1 \mathrm{~min}$. Standardized C-scores correcting for age (range $=0-10$ ) were calculated for each category. The average of these C-scores (fluency average) was used as a dependent measure. This has been regarded as a measure of semantic category verbal fluency and strategy-driven retrieval from semantic memory (Jolles et al., 1995; Lezak, 1995; Van der Elst, Van Boxtel, Van Breukelen, \& Jolles, 2006a).

\section{Verbal Working Memory}

The Auditory Verbal Learning Task (AVLT). In this test, 15 frequently used monosyllabic words were presented, one after another, in a fixed order at a rate of one every $2 \mathrm{~s}$ (Brand \& Jolles, 1985; Jolles et al., 1995; Van der Elst, Van Boxtel, Van Breukelen, \& Jolles, 2005). After the presentation of all words, participants were asked to reproduce as many words as possible (immediate recall). This procedure was repeated five times. Twenty minutes after the fifth recall, participants were asked again to recall as many words as possible (delayed recall). Word production on the first trial (AVLT Trial 1) was included as a measure of immediate memory span or working memory on the basis of previous literature (Schmidt, 1996; Spreen \& Strauss, 1998; Van der Elst et al., 2005).
Estimate of IQ: Doing sums, mental rotation, and analogies. The subtask "doing sums" required the participant to, within a time period of $1 \mathrm{~min}$, correctly complete as many adding sums as possible. The subtask "mental rotation" required participants to indicate which two-dimensional shape needed to be selected from a larger set to completely fill a given space. The third subtask "analogies" can be regarded as a multiple-choice version of the well-known Similarities subtest of the Wechsler Adult Intelligence Scale-Revised (WAIS-R; Wechsler, 1981) in which participants are asked to indicate which of the five alternatives is similarly related to a given word as the two words in the example. These three subtasks are part of the GIT, which is a frequently used Dutch intelligence test (Luteijn \& van der Ploeg, 1983). The combination of these subtasks is believed to be a good approximation of a full-scale IQ (Luteijn \& van der Ploeg, 1983). The mean score was 100 $(S D=15)$. The GIT is comparable with the WAIS-R, as evidenced by a correlation between the GIT-IQ and the WAIS-IQ that ranges from .72 to .91 (Luteijn \& van der Ploeg, 1983).

\section{Data Analyses}

First, all dependent variables were examined for extreme values (i.e., scores $>3$ times the interquartile length from the median). With respect to the specificity of the analyses, it is important to note that the number of participants excluded differed for each dependent variable as follows: SCWT_3 ( $n=2$ non-ADHD participants), SCWT interference ( $n=1$ non-ADHD participant, and $n=1$ healthy control), and CST_C and CST shifting $(n=1$ healthy control). In addition, incomplete test results were found for the SCWT $\left(n=2 \mathrm{ADHD}^{+} ; n=1\right.$ non-ADHD), the CST $(n=4$ $\left.\mathrm{ADHD}^{+} ; n=1 \mathrm{ADHD}^{-}\right)$, the VFT $\left(n=3 \mathrm{ADHD}^{+}\right)$, and the $\operatorname{AVLT}\left(n=1 \mathrm{ADHD}^{+}\right)$. These data were believed to be missing at random. Missing data occurred because of technical problems during testing or because parts of the investigation that had already taken place in another setting with the participant were not reassessed. No noncompliance occurred. Adults with extreme scores or missing data were excluded pairwise from the analyses. Therefore, the degrees of freedom in the $F$ statistics varied according to the number of participants that had completed the task under study and/or the number of extreme values deleted.

Furthermore, bivariate correlational analyses between the outcome measures and demographic variables (i.e., IQ and medication) were performed to determine whether these variables should be included as covariates in the analyses (see Table 3). Only low associations were found between the executive outcome measures and IQ and medication usage (see Table 3). Therefore, the demographic measures were not included as covariates.

Separate general linear model (GLM) univariate analyses of variance were used per task with correction for unequal sample sizes; $p$ values of .05 or lower were considered statistically significant. If the omnibus $F$ test was significant, we conducted post hoc pairwise comparisons with Bonferroni corrections. Cohen's partial eta squared $\left(\eta_{p}^{2}\right)$ is reported for all group comparisons to convey effect size for GLM univariate analyses. This is done in accordance with recommendations found in academic literature (Pierce, Block, \& Aguinis, 2004), whereby the values of partial eta squared are considered equal to eta squared values (and $r$ squared) in the case of GLM univariate analyses. These correspond approx- 
Table 3

Correlations Between EF Variables, Non-EF Variables, Medication, and IQ for the Four Groups $(N=212)$

\begin{tabular}{|c|c|c|c|c|c|c|c|c|c|c|}
\hline Variable & 1 & 2 & 3 & 4 & 5 & 6 & 7 & 8 & 9 & 10 \\
\hline 1. SCWT_3 & - & $.93^{* *}$ & $.41^{* *}$ & $.21^{* *}$ & $-.35^{* *}$ & $-.24^{* *}$ & $.68^{* *}$ & $.50^{* *}$ & .09 & $-.25^{* *}$ \\
\hline 2. SCWT interference & & - & $.31^{* *}$ & $.14^{*}$ & $-.26^{* *}$ & $-.18^{* * *}$ & $.38^{* * *}$ & $.41^{* *}$ & .04 & $-.22^{* *}$ \\
\hline 3. CST_C & & & - & $.87^{* *}$ & $-.31^{* *}$ & $-.27^{* *}$ & $.41^{* *}$ & $.64^{* * *}$ & $.18^{* *}$ & $-.33^{* *}$ \\
\hline 4. CST shifting & & & & - & $-.22^{* *}$ & $-.21^{* * *}$ & $.25^{* *}$ & $.20^{* * *}$ & .11 & $-.22^{* *}$ \\
\hline 5. Fluency & & & & & - & $.22^{* * *}$ & $-.35^{* *}$ & $-.28^{* *}$ & -.03 & $.27^{* * *}$ \\
\hline 6. AVLT Trial 1 & & & & & & - & $-.26^{* *}$ & $-.23^{* *}$ & $-.19^{* *}$ & $.24^{* * *}$ \\
\hline 7. SCWT_12 & & & & & & & - & $.43^{* *}$ & $.16^{*}$ & $-.21^{* *}$ \\
\hline 8. $\mathrm{CST}_{-} \mathrm{AB}$ & & & & & & & & - & $.18^{* *}$ & $-.33^{* *}$ \\
\hline 9. Medication & & & & & & & & & - & -.05 \\
\hline 10. IQ & & & & & & & & & & - \\
\hline
\end{tabular}

Note. $\quad \mathrm{EF}=$ executive functioning; SCWT $=$ Stroop Color-Word Test CST $=$ Concept Shifting Test; AVLT $=$ Auditory Verbal Learning Task. ${ }^{*} p<.05 . \quad{ }^{* *} p<.01$.

imately to the following effect size conventions: small (.01), medium (.06), and large (.14) (Cohen, 1988).

All outcome measures were also screened for violations of assumptions associated with GLM univariate analyses. Levene's test of equality of error variances was significant for SCWT_12 $(p<.001)$, SCWT_3 $(p<.001)$, SCWT interference $(p<.001)$, CST_C $(p<.001)$, and CST shifting $(p<.001)$; therefore, additional nonparametric Kruskal-Wallis tests were performed for the SCWT and CST outcome measures. We performed all statistical analyses using the SPSS package for Windows 11.0.

\section{Results}

Means and standard errors for each outcome measure according to group are displayed in Table 4. With regard to the SCWT, the following results were found: Significant group differences were found on averaged total time to complete Card I and Card II (SCWT_12): $\mathrm{ADHD}^{+}$participants $(p<.001)$ and non-ADHD adults $(p=.019)$ performed slower than the healthy control participants. Additionally, a significant main effect of group was found on the SCWT Card III (SCWT_3): $\mathrm{ADHD}^{+}$adults were slower than the healthy control participants $(p=.027)$. On the SCWT interference score, this main effect on SCWT_3 attenuated, and thereby no significant group differences were found for this measure. Notably, nonparametric tests were indicated with violations of the assumptions of GLM univariate analyses. However, given that the nonparametric Kruskal-Wallis tests revealed comparable results (with the exception of the absence of significant main effect on SCWT_3; $p>$.05), the parametric tests are reported here and in Table 4.

Furthermore, no significant group differences were found on the averaged total time to complete Cards A and B (CST_AB). However, significant group differences were found on the CST Card C (CST_C) and the CST shifting score. On the CST_C, we found that adults with $\mathrm{ADHD}^{+}$had significantly lower scores than the healthy control participants $(p=.015)$. Additionally, the $\mathrm{ADHD}^{-}$ group was significantly slower than the non-ADHD group ( $p=$

Table 4

Means (and Standard Errors) of Performance Test Scores on Executive Function Domains

\begin{tabular}{|c|c|c|c|c|c|c|c|c|c|}
\hline & $\begin{array}{c}\mathrm{ADHD}^{-}(1) \\
(n=20)\end{array}$ & $\begin{array}{c}\mathrm{ADHD}^{+}(2) \\
(n=22)\end{array}$ & $\begin{array}{c}\text { Non-ADHD (3) } \\
\quad(n=34)\end{array}$ & $\begin{array}{c}\text { Controls (4) } \\
(n=136)\end{array}$ & & & & & \\
\hline Domain & $M(S E)$ & $M(S E)$ & $M(S E)$ & $M(S E)$ & $F$ & $d f \mathrm{~s}$ & $p$ & Bonferroni & $\eta_{p}^{2}$ \\
\hline \multicolumn{10}{|l|}{ Interference control } \\
\hline SCWT_3 (s) & $88.53(4.38)$ & $96.77(4.38)$ & $82.78(3.51)$ & $83.30(1.68)$ & 3.09 & 3,203 & .028 & $2<4$ & .044 \\
\hline SCWT interference (s) & $38.80(3.47)$ & $41.25(3.47)$ & $34.10(2.74)$ & $36.00(1.33)$ & 1.06 & 3,203 & $n s$ & & .016 \\
\hline \multicolumn{10}{|l|}{ Mental flexibility } \\
\hline CST_C (s) & $34.55(1.98)$ & $33.06(2.03)$ & $27.87(1.48)$ & $26.43(0.74)$ & 7.22 & 3,202 & $<.001$ & $\begin{aligned} 1,2 & <4 \\
1 & <3\end{aligned}$ & .097 \\
\hline CST shifting (s) & $13.38(10.36)$ & $12.87(11.20)$ & $8.38(5.72)$ & $8.60(6.92)$ & 7.24 & 3,202 & $<.001$ & $\begin{array}{r}1,2<4 \\
1<3\end{array}$ & .097 \\
\hline \multicolumn{10}{|l|}{ Verbal fluency } \\
\hline $\begin{array}{l}\text { Fluency (C score) } \\
\text { Working memory }\end{array}$ & $5.90(0.32)$ & $5.92(0.33)$ & $5.54(0.25)$ & $6.33(0.12)$ & 3.04 & 3,205 & .030 & $3<4$ & .043 \\
\hline AVLT Trial 1 & $4.40(0.40)$ & $4.80(0.39)$ & $5.35(0.31)$ & $5.94(0.15)$ & 6.14 & 3, 207 & .001 & $1,2<4$ & .082 \\
\hline \multicolumn{10}{|l|}{ Output speed } \\
\hline SCWT_12 (s) & $49.73(1.79)$ & $55.52(1.79)$ & $51.52(1.39)$ & $46.87(0.68)$ & 8.61 & 3,205 & $<.001$ & $2,3<4$ & .112 \\
\hline CST_AB (s) & $21.16(0.98)$ & $20.19(1.01)$ & $19.48(0.73)$ & $18.80(0.37)$ & 1.90 & 3,202 & $n s$ & & .028 \\
\hline
\end{tabular}

Note. $\mathrm{ADHD}=$ attention-deficit/hyperactivity disorder; $\mathrm{ADHD}^{-}=\mathrm{ADHD}$ without comorbidity $; \mathrm{ADHD}^{+}=\mathrm{ADHD}$ with comorbidity; $\mathrm{SCWT}=\mathrm{Stroop}$ Color-Word Test; $\mathrm{s}=$ seconds; CST $=$ Concept Shifting Test; AVLT $=$ Auditory Verbal Learning Task. 
$.044)$ and the healthy control participants $(p=.001)$. Post hoc analyses on the CST shifting score revealed results highly comparable with the CST_C. Nonparametric tests for CST_C and CST shifting revealed results that were comparable with the GLM univariate tests, and therefore the parametrics are reported (see Table 4).

With regard to the scores on the VFT, the results indicate that the non-ADHD group performed worse than the healthy control participants $(p=.030)$. No other group differences were found. With respect to the AVLT Trial 1, significant group differences in performance were found. Both the $\mathrm{ADHD}^{-}$and $\mathrm{ADHD}^{+}$groups had significantly lower scores on this first trial when compared with the healthy control participants $\left(\mathrm{ADHD}^{+}\right.$vs. healthy control participants, $p=.048$; $\mathrm{ADHD}^{-}$vs. healthy control participants, $p=.003)$.

In general and as depicted in Table 3, the correlations between the tasks across the four EF domains were low, thus suggesting that the EF measures were relatively independent of one another. Correlations between tasks within an EF domain (i.e., SCWT and CST) were high, suggesting that they were measuring the same domain. Correlations between the EF measure and non-EF measures were also low. The only exceptions were (a) a high positive correlation between SCWT_3 and both non-EF output speed measures (SCWT_12 and CST_AB), and (b) a high positive correlation between CST_C and the non-EF CST_AB measure.

\section{Discussion}

The aims of the study reported were to examine (a) the relationship between adult ADHD and four domains of EF, and (b) the impact of comorbidity on this relationship. This was done in an effort to determine whether ADHD does indeed generate deficits on all four EF domains as suggested by Barkley's (1997) model. Therefore, test performance of two ADHD groups $\left(\mathrm{ADHD}^{+}\right.$and $\mathrm{ADHD}^{-}$) and two control groups (non-ADHD and healthy control participants) was contrasted.

On the basis of the pairwise comparisons, we found observable ADHD-related deficits (i.e., verbal working memory deficits and deficits in concept shifting) that are independent of comorbidity. The finding that adults with ADHD have problems with verbal working memory measured by the AVLT Trial 1 corresponds with previously reported studies (Holdnack et al., 1995; Lovejoy et al., 1999; K. R. Murphy et al., 2001; Nigg, 2001; Walker et al., 2000). Difficulties with verbal working memory have also been reported in clinical practice as forgetfulness in daily activities (APA, 1994). Additionally, the medium effect size on a measure of working memory found in our study is consistent with what has been found in a previous meta-analytic study (Hervey et al., 2004). In addition, this finding that ADHD adults performed worse on immediate recall of AVLT Trial 1 than healthy controls may reflect a disturbance in the verbal storage component demands of Baddeley's (1986) model of working memory. Indeed, previous work has demonstrated that deficits on immediate recall of verbal word list learning tasks can be best interpreted by a deficient phonological loop (see Hervey et al.'s, 2004, review). This storage system of the working memory model (Baddeley, 1986) is involved in holding verbal information online and has a limited capacity. Our finding supports this hypothesis. Evidently, this finding has important clinical implications. Adults with ADHD may benefit from work- ing memory training programs, and this should be investigated further. It is possible that these group differences may be attributable to an inefficient use of strategies for processing new verbally unrelated information. This inefficient strategy use has previously been demonstrated in patients with frontal-lobe lesions (Gershberg \& Shimamura, 1995; Stone, Gabrieli, Stebbins, \& Sullivan, 1998). Further research on underlying verbal learning strategies and learning processes in adults with ADHD is necessary to confirm our findings.

It is also important to note that, in our study, concept shifting deficits were also specifically related to both ADHD groups. This finding corresponds with previous review studies conducted with adults diagnosed with ADHD (Hervey et al., 2004; Woods et al., 2002). These studies demonstrated that, when compared with healthy control participants, adults with ADHD performed worse on the Trail Making Test task, which is a task that requires advanced planning and mental flexibility. Also, in correspondence with earlier studies (Hervey et al., 2004), our study also found a medium effect size on this task. Additionally, our finding that adults with ADHD, irrespective of their comorbidity, have more difficulties with the self-regulation of their behavior and with shifting from one concept to another supports not only recent theoretical models on ADHD but also the contention that these deficits may be uniquely related to ADHD (Barkley, 1998; Nigg, 2001). However, caution is still needed in this conclusion on specific ADHD deficits, as the potential role of comorbidity in this ADHD with comorbidity group cannot be fully ruled out. These problems with shifting from one concept to another and with self-control have also been reported in clinical practice as complaints relating to the failure to organize and complete activities (APA, 1994). Similar to our conclusions on verbal working memory, we contend that the difficulties adults with ADHD experience in regulating their behavior and shifting from one concept to another may be attributable to the use of an inefficient strategy to complete these tasks.

In contrast to our findings on working memory and concept shifting, no ADHD-related effects were found for interference control or verbal fluency. Although similar findings have been reported by other investigators (Corbett \& Stanczak, 1999; Downey, Stelson, Pomerleau, \& Giordani, 1997; Gansler et al., 1998; Johnson et al., 2001; Walker et al., 2000), these results do contradict the findings of other studies described earlier. For example, Barkley's $(1997,1998)$ frequently cited disinhibition model states that deficits in response inhibition, such as interference control, are the core deficits found in individuals with ADHD and that these deficits in response inhibition lead secondarily to general executive function impairments, such as verbal fluency deficits. Unfortunately, most models and studies relating to EF impairments and ADHD have been conducted or have been applied to children with ADHD. However, Hervey et al. (2004) did conduct a metaanalytic study with adults and found that, when compared with healthy control participants, adults with ADHD performed more poorly on verbal fluency tests. Additionally, and in congruence with our study, these authors demonstrated low effect sizes for the Stroop interference. It is possible that the severity of executive dysfunction declines as individuals with ADHD age because they learn to compensate for these deficits in everyday life and thus also in neuropsychological testing settings. Examples of compensatory strategies include expressing hyperactivity though inner restless- 
ness rather that outward displays of hyperactivity, avoiding situations that cause problems or make symptoms more apparent, using work schedules to organize, and delegating boring or complex tasks to partners or significant others (Amstrong, Hayes, \& Martin, 2001).

Furthermore, we found poor performance on verbal fluency in the non-ADHD group in comparison with healthy controls. Such a verbal fluency deficit has also been found in individuals with different kinds of psychiatric conditions (such as personality disorders, mood and anxiety disorders, and substance-related disorders), which were also diagnosed in the majority of our nonADHD participants (Den Hartog, 2002; Fossati, Guillaume, Ergis \& Allilaire, 2003; Moritz et al., 2002; Pope, Gruber, Hudson, Huestis, \& Yurgelun-Todd, 2001; Wilens et al., 2003). Our finding of no deficits in verbal fluency in adults with ADHD is in line with two previous studies (Barkley, 1998; Johnson et al., 2001). However, the results remain mixed about this issue in adult ADHD (see Woods et al., 2002). Future research on quantitative analyses of word production over time and response organization strategies (e.g., clustering, switching) would be promising in detecting mechanisms underlying verbal fluency performance in adult ADHD. In addition, our analyses showed no significant group differences between the non-ADHD group and the ADHD groups, suggesting that these groups were rather comparable in their performance. This is consistent with an earlier study by Walker et al. (2000). These authors found no significant differences between an ADHD group and a psychiatric group with mood and anxiety disorder on measures of verbal fluency. Inspection of the scores also suggests that there was no clinically significant effect found for the nonADHD participants, as their score fell within the normal/average range.

With respect to our non-EF task demands-including information processing speed, automation of skills, and/or (selective) attention - our study demonstrated deficits on SCWT_12 for both the $\mathrm{ADHD}^{+}$group and the non-ADHD group. Because these deficits occurred only in these two groups and not in the ADHD ${ }^{-}$ group, we contend that these deficits are likely attributable to the presence of comorbidity rather than to ADHD. Evidently, this finding does not correspond with the cognitive subtype hypothesis (Rucklidge \& Tannock, 2002). Strikingly, the findings of our study suggest that effects due to the presence of ADHD and one or more comorbid disorders result from the additive combination of the correlates of each disorder when they occur separately (Willcutt, Pennington, Olson, Chhabildas, \& Hulslander, 2005). Therefore, the nonsignificance of the interference control measure in adults with ADHD may stem from the slower reading of words and listing of colors, which are variables that are also taken into account in the interference control measures. Indeed, we did observe medium effects on the SCWT_12 in our study that corresponded with Hervey et al.'s (2004) results in which small effects on these Stroop measures were found. In contrast to the findings produced by Hervey et al., we found that, in comparison with healthy control participants, our ADHD participants did not experience more problems with both verbal and fine motor processing, as measured by the CST_AB.

An additional aspect of our study worthy of mention is the associations between tasks across the four EF domains of and between tasks within each EF domain. Our results indicate that the correlations between tasks across the four domains were low and that the correlations between tasks within a given domain (i.e., SCWT and CST) were high. This suggests that the four EF domains were independent of one another and thereby supports our contention that the different tasks measured different underlying EF constructs. We also found low correlations between the majority of the EF and non-EF measures. High correlations between the SCWT_3 and both non-EF output speed measures (SCWT_12 and CST_AB) and between CST_C and the non-EF CST_AB measure were the only exceptions, and these were expected given that the non-EF measures were also involved in the SCWT_3 and CST_C tasks. Our finding supports the idea put forth by Sergeant et al. (2002) that the Stroop task and the CST task measures are rather nonunitary constructs that cannot easily be distinguished from one another. We therefore endeavored to control for these non-EF measures to examine the isolated EF deficits, and indeed, when controlling for these measures, no deficits appeared on the interference control measure in adults with ADHD. Clearly, this suggests that different EF and non-EF processes are involved in the Stroop task.

In line with this, we contend that our results can be explained by a general processing speed load problem in both the ADHD and non-ADHD clinical groups. Many of the tasks, including the SCWT and CST, were highly dependent on speed of processing. We therefore argue that lower load of processing speed was confined to ADHD and the clinical comorbidity groups. Indeed, simple processing speed difficulties have also been found in mood disorders (Den Hartog, 2002), which were part of our clinical non-ADHD group. In addition, problems with higher demands on processing speed load were more specifically confined to adult ADHD. Likewise, in pediatric ADHD, processing speed has been suggested as a potential common deficit in comorbidity between ADHD and reading disorders (Willcutt, Pennington, et al., 2005). Our results suggest that processing speed may also be a worthwhile focus for future research on the neuropsychological correlates of adult ADHD and comorbid disorders.

\section{Limitations and Future Research}

The findings reported here need to be interpreted in light of some limitations. First, ADHD is a heterogeneous condition with different subtypes (APA, 1994) and a high rate of comorbidity (Milberger et al., 1995; Millstein et al., 1997; K. R. Murphy et al., 2002). Like many other studies on ADHD (see Hervey et al., 2004), the heterogeneity across and within the ADHD sample posed a potential problem in the study presented here. The $\mathrm{ADHD}^{+}$group was very heterogeneous and this may have limited the degree to which we were able to properly interpret the results of the study. This was unavoidable given that, to date, the exact effects of the various comorbid conditions on neuropsychological performance remain unknown and inconsistent. This is exemplified by the following: In a study conducted by K. R. Murphy et al. (2001), the authors addressed the effect of comorbidity and concluded that the presence of additional psychopathology (i.e., depressive, anxious, or oppositional symptoms) did not affect neuropsychological performance. However, in the meta-analytic study by Hervey et al. (2004), the authors found that adults diagnosed with both ADHD and comorbid disorder displayed greater neuropsychological deficits than individuals with only ADHD and no comorbidity. Whereas the above mentioned studies contradict each 
other, our study supports aspects of both. Nonetheless, a limitation that remains is our failure to control for the range of comorbid disorders and our treatment of the group as a whole. We therefore are unable to draw any definitive conclusions about the impact of an isolated or additive effect of one or more comorbid disorders in the adults with ADHD. Nonetheless, given that the primary focus of our study was placed on determining deficits in adults with ADHD and only secondarily on the effect of comorbidity, we consider our decision to control for comorbidity by comparing a pure ADHD group to both a group with comorbid ADHD and a clinical non-ADHD group to be sufficient.

An additional limitation of our study relates to ADHD subtype differences. We were unable to make comparisons between ADHD subtypes because of the small ADHD subtype sample sizes. Additionally, subtype comparisons were not performed because they were likely to decrease the power of our study or generate Type I and II errors. Nonetheless, we hypothesize, on the basis of the findings of earlier studies (Barkley, 1997, 1998; Nigg et al., 2002), that had the subtypes been compared, EF deficits would have only been found in the adults with the ADHD combined subtype and not in adults with the ADHD inattentive subtype. However, in a recent study by K. R. Murphy et al. (2001), no EF differences between different adult ADHD subtypes were found. Moreover, further research exploring subtype differences on tasks with different load on processing speed may shed more light on the differential correlates and mechanisms involved in ADHD disorders.

A further limitation of our study is that, because of our sample size, we examined only four of the many functions included in the domain EF. We were therefore unable to provide a complete breakdown of intact and impaired executive functions in adults with ADHD. However, we were able to examine the aspects of EF most commonly reported as impaired aspects in children with ADHD and also the impact of comorbidity on these cognitive functions to determine the degree to which findings with children are consistent and generalize to adults with ADHD.

A last point of concern involves our approach employed to assess our EF and non-EF components. The subtraction approach used to indicate EF components (e.g., Stroop interference control) remains controversial, and other measures-such as the proportion score- have been suggested to be a more sophisticated measure (Stuss, Floden, Alexander, Levine, \& Katz, 2001). However, our subtraction approaches for the SCWT as well as the CST are frequently reported in other studies and have proven to be valid measures of EF components (Meijer, 2006; Valentijn et al., 2005; Van Boxtel et al., 1998; Van der Elst et al., 2006b; Van der Elst et al., in press; van Hooren, 2004). In addition, exploratory analyses of the proportion of Stroop and CST interference scores, on the basis of the article by Stuss et al. (2001), have revealed comparable results. Thereby, we found it justified to implement our subtraction approach.

We recommend that future researchers investigate the usefulness of a larger test battery that includes a wider range of EF and non-EF domains. We also recommend the analyses of more qualitative outcomes, such as number of errors, self corrections, and time segments in verbal fluency. Lastly, we recommend a longitudinal assessment of EF domains to determine the stability of the impairments in the clinical groups. By doing this, a complete breakdown of intact and impaired executive function in adults with ADHD with and without comorbidity can be delineated according to ADHD subtype.

\section{Conclusions}

In conclusion, the current study has demonstrated specific deficits in two domains of EF, namely verbal working memory and concept shifting, for adults with pure $\mathrm{ADHD}\left(\mathrm{ADHD}^{-}\right)$and for adults characterized by $\mathrm{ADHD}$ and comorbidity $\left(\mathrm{ADHD}^{+}\right)$. No ADHD-related effects were found for interference control or verbal fluency. Our study has also demonstrated that, in contrast to the group of adults with pure ADHD, the group with both ADHD and a comorbid disorder and the group termed non-ADHD displayed processing speed problems. The results thus suggest that these deficits are due to the effect of comorbidity rather than ADHD. The results reported here do not fully correspond with Barkley (1997), who found - in children with ADHD - a more general weakness in executive function or all EF domains. Our findings do, however, support the hypothesis that general EF weaknesses are neither necessary nor sufficient to cause all cases of ADHD (Willcutt, Doyle, Nigg, Faraone, \& Pennington, 2005).

\section{References}

American Psychiatric Association. (1994). Diagnostic and statistical manual of mental disorders (4th ed.). Washington, DC: Author.

Amstrong, C. L., Hayes, K. M., \& Martin, R. (2001). Neurocognitive problems in attention deficit disorder: Alternative concepts and evidence for impairment in inhibition of selective attention. Annals of New York Academy of Sciences, 931, 196-215.

Baddeley, A. (1986). Working memory. Oxford, England: Clarendon Press.

Barkley, R. A. (1997). Behavioral inhibitions, sustained attention, and executive functions: Constructing a unifying theory of ADHD. Psychological Bulletin, 121, 65-94.

Barkley, R. A. (1998). Attention-deficit/hyperactivity disorder: A handbook for diagnosis and treatment (2nd ed.). New York: Guilford Press.

Barkley, R. A., Murphy, K. R., \& Bush, T. (2001). Time perception and reproduction in young adults with attention deficit hyperactivity disorder. Neuropsychology, 15(3), 351-360.

Barkley, R. A., Murphy, K. R., DuPaul, G. J., \& Bush, T. (2002). Driving in young adults with attention deficit hyperactivity disorder: Knowledge, performance, adverse outcomes, and the role of executive functioning. Journal of the International Neuropsychological Society, 8, 655-672.

Barkley, R. A., Murphy, K. R., \& Kwasnik, D. (1996). Psychological adjustment and adaptive impairments in young adults with ADHD. Journal of Attention Disorders, 1(1), 41-54.

Biederman, J., \& Faraone, S. V. (2002). Current concepts on the neurobiology of attention-deficit/hyperactivity disorder. Journal of Attention Disorders, 6, S7-S17.

Biederman, J., Faraone, S. V., Mick, E., Spencer, T., Wilens, T., Kiely, K., et al. (1995). High risk for attention deficit hyperactivity disorder among children of parents with childhood onset of the disorder: A pilot study. American Journal of Psychiatry, 152, 431-435.

Biederman, J., Faraone, S. V., Taylor, A., Sienna, M., Williamson, S., \& Fine, C. (1998). Diagnostic continuity between child and adolescent ADHD: Findings from a longitudinal clinical sample. Journal of the American Academy of Child and Adolescence Psychiatry, 37(30), 305313. 
Brand, N., \& Jolles, J. (1985). Learning and retrieval rate of words presented auditory and visually. Journal of General Psychology, 112, 201-210.

Bush, G., Frazier, J. A., Rauch, S. L., Seidman, L. J., Whalen, P. J., Jenike, M. A., et al. (1999). Anterior cingulate cortex dysfunction in attentiondeficit/hyperactivity disorder revealed by fMRI and the counting group. Biological Psychiatry, 45(12), 1542-1552.

Campbell, D., \& Stanley, J. (1963). Experimental and quasi-experimental designs for research. Boston: Houghton Mifflin.

Cohen, J. (1988). Statistical power analysis for the behavioral sciences (2nd ed.). Hillsdale, NJ: Erlbaum.

Corbett, B., \& Stanczak, D. E. (1999). Neuropsychological performance of adults evidencing attention-deficit/hyperactivity disorder. Archives of Clinical Neuropsychology, 14, 373-387.

Denckla, M. B. (1996). A theory and model of executive function: A neuropsychological perspective. In G. R. Lyon \& N. A. Krasnegor (Eds.), Attention, memory, and executive function (pp. 263-277). Baltimore: Brooks.

Den Hartog, M. (2002). Cognitive performance in depression: Patterns and determinants. Unpublished doctoral dissertation, Maastricht University, the Netherlands.

Dinn, W. M., Robbins, N. C., \& Harris, C. L. (2001). Adult attentiondeficit/hyperactivity disorder: Neuropsychological correlates and clinical presentation. Brain and Cognition, 46(1-2), 114-121.

Downey, K. K., Stelson, F. W., Pomerleau, O. F., \& Giordani, B. (1997). Adult attention deficit hyperactivity disorder: Psychological test profiles in a clinical population. Journal of the Nervous and Mental Disorders, $185,32-38$.

Durston, S. (2003). A review of the biological bases of ADHD: What have we learned from imaging studies? Mental Retardation and Developmental Disabilities, 9, 184-195.

Faraone, S. V., Biederman, J., Spencer, T., Wilens, T., Seidman, L. J., Mick, E., et al. (2000). Attention-deficit/hyperactivity disorder in adults: An Overview. Biological Psychiatry, 48, 9-20.

Fossati, P., Guillaume, L. B., Ergis, A.-M., \& Allilaire, J.-F. (2003). Qualitative analysis of verbal fluency in depression. Psychiatry Research, 117, 17-24.

Gansler, D. A., Fucetola, R., Krengel, M., Stetson, S., Zimering, R., \& Makary, C. (1998). Are there cognitive subtypes in adult attentiondeficit/hyperactivity disorder? The Journal of Nervous and Mental Disease, 186, 776-781.

Gershberg, F. B., \& Shimamura, A. P. (1995). Impaired use of organizational strategies in free recall following frontal lobe damage. Neuropsychologia, 13, 1305-1333.

Hammes, J. (1973). De Stroop Kleur-Woord Test: Handleiding [The Stroop Color-Word Test: Manual]. Amsterdam: Swets \& Zeitlinger.

Hervey, A. S., Epstein, J. N., \& Curry, J. F. (2004). Neuropsychology of adults with attention-deficit/hyperactivity disorder: A meta-analytic review. Neuropsychology, 18(3), 485-503.

Holdnack, J. A., Moberg, P. J., Arnold, S. E., Ruben, C., Gur, R. C., \& Gur, R. E. (1995). Speed of processing and verbal learning deficits in adults diagnosed with attention deficit hyperactivity disorder. Neuropsychiatry, Neuropsychology, and Behavioural Neurology, 8(4), 282-292.

Houx, P. J., \& Jolles, J. (1993). Age-related decline of psychomotor speed: Effects of age, brain health, sex, and education. Perceptual and Motor Skills, 76(1), 195-211.

Houx, P. J., Jolles, J., \& Vreeling, F. W. (1993). Stroop interference: Aging effects assessed with the Stroop Color-Word Test. Experimental Aging Research, 19(3), 209-224.

Houx, P. J., Vreeling, F. W., \& Jolles, J. (1991). Age associated cognitive decline is related to biological life-events. In R. C. Mclachlan, B. Winblad, \& H. M. Wisniewski (Eds.), Alzheimer's disease: Basic mechanisms, diagnosis, and therapeutic strategies (pp. 353-359). Chichester, England: Wiley.
Johnson, D. E., Epstein, J. N., Waid, L. R., Latham, P. K., Voronin, K. E., \& Anton, R. F. (2001). Neuropsychological performance deficits in adults with attention-deficit/hyperactivity disorder. Archives of Clinical Neuropsychology, 16, 587-604.

Jolles, J., Houx, P. J., Van Boxtel, M. P. J., \& Ponds, R. W. H. M. (1995). The Maastricht Aging Study: Determinants of cognitive aging. Maastricht, the Netherlands: Neuropsych Publishers.

Lezak, M. D. (1995). Neuropsychological assessment (3rd ed.). Oxford, England: Oxford University Press.

Lovejoy, D. W., Ball, J. D., Keats, M., Stutts, M. L., Spain, E. H., Janda, L., et al. (1999). Neuropsychological performance of adults with attention deficit hyperactivity disorder (ADHD): Diagnostic classification estimates for measures of frontal lobe/executive functioning. Journal of the International Neuropsychological Society, 5, 222-233.

Luteijn, F., \& van der Ploeg, F. A. E. (1983). Handleiding Groninger Intelligentietest (GIT) [Manual Groningen Intelligence Test (GIT)]. Lisse, the Netherlands: Swets \& Zeitlinger.

Manuzza, S., \& Klein, R. G. (2000). Long-term prognosis in attentiondeficit/ hyperactivity disorder. Child and Adolescent Psychiatric Clinics of North America, 9(3), 711-726.

Meijer, W. (2006). Cognitive aging: Effects of education and task demands. Unpublished doctoral dissertation, Maastricht University, the Netherlands.

Metsemakers, J. F. M., Höppener, P., Knottnerus, J. A., Kocken, R. J. J., \& Limonard, C. B. G. (1992). Computerized health information in the Netherlands: A registration network of family practices. British Journal of General Practice, 42, 102-106.

Milberger, S., Biederman, J., Faraone, S. V., Murphy, J., \& Tsuang, M. T. (1995). Attention deficit hyperactivity disorder and comorbid disorders: Issues of overlapping symptoms. American Journal of Psychiatry, 152, 1793-1799.

Millstein, R. B., Wilens, T. E., Biederman, J., \& Spencer, T. J. (1997). Presenting ADHD symptoms and subtypes in clinically referred adults with ADHD. Journal of Attention Disorders, 2(3), 159-166.

Moritz, S., Birkner, C., Kloss, M., Jahn, H., Hand, I., Haasen, C., et al. (2002). Executive functioning in obsessive-compulsive disorder, unipolar depression, and schizophrenia. Archives of Clinical Neuropsychology, 17, 477-483.

Murphy, K. R., Barkley, R. A., \& Bush, T. (2001). Executive functioning and olfactory identification in young adults with attention-deficit/hyperactivity disorder. Neuropsychology, 15, 211-220.

Murphy, K. R., Barkley, R. A., \& Bush, T. (2002). Young adults with attention-deficit/hyperactivity disorder: Subtype differences in comorbidity, educational, and clinical history. The Journal of Nervous and Mental Disease, 190(3), 147-157.

Murphy, P. (2002). Cognitive functioning in adults with attention-deficit/ hyperactivity disorder. Journal of Attention Disorders, 5(4), 203-209.

Nigg, J. T. (2001). Is ADHD a disinhibitory disorder? Psychological Bulletin, 127(5), 571-598.

Nigg, J. T., Blaskey, L. G., Huang-Pollock, C. L., \& Rappley, M. D. (2002). Neuropsychological executive functions and DSM-IV ADHD subtypes. Journal of the American Academy of Child and Adolescence Psychiatry, 41(1), 59-66.

Oosterlaan, J., Logan, G. D., \& Sergeant, J. A. (1998). Response inhibition in $\mathrm{AD} / \mathrm{HD}, \mathrm{CD}$, comorbid $\mathrm{AD} / \mathrm{HD}$, anxious, and control children: $\mathrm{A}$ meta-analysis of studies with the stop task. Journal of Child Psychology and Psychiatry, 39, 411-425.

Pennington, B. F., \& Ozonoff, S. (1996). Executive functions and developmental psychopathology. Journal of Child Psychology and Psychiatry, 37, 51-87.

Pierce, C. A., Block, R. A., \& Aguinis, H. (2004). Cautionary note on reporting eta-squared values from multifactor ANOVA designs. Educational and Psychological Measurement, 64(6), 916-924. 
Pope, H. G., Gruber, A. J., Hudson, J. I., Huestis, M. A., \& Yurgelun-Todd, D. (2001). Neuropsychological performance in long-term cannabis users. Archives of General Psychiatry, 58, 909-915.

Rapport, L. J., Van Voorhis, A., Tzelepis, A., \& Friedman, S. R. (2001). Executive functioning in adult attention-deficit hyperactivity disorder. The Clinical Neuropsychologist, 15, 479-491.

Reitan, R. M. (1958). Validity of the Trail Making Test as an indicator of organic brain damage. Perceptual and Motor Skills, 8, 271-276.

Rubia, K., Overmeyer, S., Taylor, E., Brammer, M., Williams, S. C., Simmons, A., et al. (1999). Hypofrontality in attention deficit hyperactivity disorder during higher-order motor control: A study with functional MRI. American Journal of Psychiatry, 156, 891-896.

Rucklidge, J. J., \& Tannock, R. (2002). Neuropsychological profiles of adolescents with ADHD: Effects of reading difficulties and gender. Journal of Child Psychology and Psychiatry, 43, 988-1003.

Salthouse, T. A. (1996). The processing-speed theory of adult age differences in cognition. Psychological Review, 103(3), 403-428.

Schmidt, M. (1996). Rey Auditory Verbal Learning Test: A handbook. Los Angeles: Western Psychological Services.

Seidman, L. J., Biederman, J., Faraone, S. V., Weber, W., \& Ouellette, C. (1997). Toward defining a neuropsychology of attention-deficit/hyperactivity disorder: Performance of children and adolescents from a large clinically referred sample. Journal of Consulting and Clinical Psychology, 65(1), 150-160.

Seidman, L. J., Biederman, J., Weber, W., Hatch, M., \& Faraone, S. V. (1998). Neuropsychological functioning in adults with attention-deficit/ hyperactivity disorder. Biological Psychiatry, 44, 260-268.

Seidman, L. J., Doyle, A., Fried, R., Valera, E., Crum, K., \& Mattews, L. (2004). Neuropsychological function in adults with attention-deficit/ hyperactivity disorder. Psychiatric Clinics of North America, 27, 261282.

Seidman, L. J., Valera, E. M., \& Makris, N. (2005). Structural brain imaging of attention-deficit/hyperactivity disorder. Behavioral Psychiatry, 57, 1263-1272.

Sergeant, J. A., Geurts, H., \& Oosterlaan, J. (2002). How specific is a deficit of executive functioning for attention-deficit/hyperactivity disorder? Behavioural Brain Research, 130, 3-28.

Spreen, O., \& Strauss, E. (1998). A compendium of neuropsychological tests: Administration, norms, and commentary (2nd ed.). New York: Oxford University Press.

Stone, M., Gabrieli, J. D. E., Stebbins, G. T., \& Sullivan, E. V. (1998). Working and strategic memory deficits in schizophrenia. Neuropsychology, 12(2), 278-288.

Stroop, J. R. (1935). Studies of interference in serial verbal reactions. Journal of Experimental Psychology, 18, 643-662.

Stuss, D. T., Floden, D., Alexander, M. P., Levine, B., \& Katz, D. (2001). Stroop performance in focal lesion patients: Dissociation of processes and frontal lobe lesion location. Neuropsychologia, 39, 771-786.

Vaidya, C. J., Austin, G., Kirkorian, G., Ridlehuber, H. W., Desmond, J. E., Glover, G. H., et al. (1998). Selective effects of methylphenidate in attention deficit hyperactivity disorder: A functional magnetic resonance study. Proceedings of the National Academy of Sciences, USA, 95, 14994-14999.

Valentijn, S. A., Van Boxtel, M. P., Van Hooren, S. A., Bosma, H., Beckers, H. J., Ponds, R. W., et al. (2005). Change in sensory functioning predicts change in cognitive functioning: Results from a 6-year follow-up in the Maastricht Aging Study. Journal of the American Geriatrics Society, 53(3), 374-380.

Van Boxtel, M. P. J., Buntinx, F., Houx, P. J., Metsemakers, J. F. M., Knottnerus, A., \& Jolles, J. (1998). The relation between morbidity and cognitive performance in a normal aging population. Journal of Gerontology, 53A(2), M147-M154.

Van der Elst, W., Van Boxtel, M. P. J., Van Breukelen, G. J. P., \& Jolles, J. (2005). Rey's Verbal Learning Test: Normative data for 1,855 healthy participants aged 24-81 years and the influence of age, sex, education, and mode of presentation. Journal of the International Neuropsychological Society, 11, 290-302.

Van der Elst, W., Van Boxtel, M. P. J., Van Breukelen, G. J. P., \& Jolles, J. (2006a). Normative data for the Animal, Profession and Letter M Naming verbal fluency tests for Dutch speaking participants and the effects of age, education, and sex. Journal of the International Neuropsychological Society, 12, 80-89.

Van der Elst, W., Van Boxtel, M. P. J., Van Breukelen, G. J. P., \& Jolles, J. (2006b). The Stroop Color-Word Test: Influence of age, sex, and education; and normative data for a large sample across the adult age range. Assessment, 13(1), 62-79.

Van der Elst, W., Van Boxtel, M. P. J., Van Breukelen, G. J. P., \& Jolles, J. (in press). The Concept Shifting Test: Adult normative data. Psychological Assessment.

van Hooren, S. (2004). Successful cognitive aging: Executive functioning, determinants, and interventions. Unpublished doctoral dissertation, Maastricht University, the Netherlands.

Vink, M., \& Jolles, J. (1985). A new version of the Trial Making Test as an information processing task. Journal of Clinical Psychology, 7, 162.

Walker, A. J., Shores, E. A., Trollor, J. N., Lee, T., \& Sachdev, P. S. (2000). Neuropsychological functioning of adults with attention deficit hyperactivity disorder. Journal of Clinical and Experimental Neuropsychology, 22, 115-124.

Wechsler, D. (1981). Wechsler Adult Intelligence Scale-Revised. New York: Psychological Corporation.

Weiss, G., \& Trokenberg-Hechtman, L. (1993). Hyperactive children grown up. New York: Guilford Press.

Wilens, T. E., Biederman, J., Wozniak, J., Gunawardene, S., Wong, J., \& Monutaux, M. (2003). Can adults with attention-deficit/hyperactivity disorder be distinguished from those with comorbid bipolar disorder? Findings from a sample of clinically referred adults. Society of Biological Psychiatry, 54, 1-8.

Willcutt, E. G., Doyle, A. E., Nigg, J. T., Faraone, S. V., \& Pennington, B. F. (2005). Validity of the executive function theory of AttentionDeficit/Hyperactivity Disorder: A meta-analytic review. Biological Psychiatry, 57, 1336-1346.

Willcutt, E. G., Pennington, B. F., Olson, R. K., Chhabildas, N., \& Hulslander, J. (2005). Neuropsychological analyses of comorbidity between reading disability and attention deficit hyperactivity disorder: In search of the common deficit. Developmental Neuropsychology, 27(1), 35-78.

Woods, S. P., Lovejoy, D. W., \& Ball, J. D. (2002). Neuropsychological characteristics of adults with ADHD: A comprehensive review of initial studies. The Clinical Neuropsychologist, 16(1), 12-34.

Received June 7, 2006

Revision received June 26, 2007 Accepted July 11, 2007 